\title{
Maeztu y Portugal. Análisis político e intelectual sobre la Primera República (1910-1926)*
}

\author{
Pablo Sánchez Garrido \\ Universidad San Pablo CEU \\ psanchez.ihum@ceu.es
}

RESUMEN: En este artículo se desarrolla un análisis de los textos que Maeztu realizó sobre Portugal durante el periodo de la I República (1910-1926), principalmente sus crónicas de 1910, su serie de «Cartas de Portugal» (1922-23) y otras fuentes similares. Para su examen, se ha recurrido a un análisis contextualizado dividiendo las fuentes en sus dos temáticas fundamentales: la política y la cultural. El análisis de estos textos de naturaleza política y cultural es especialmente relevante para conocer no solo el citado periodo desde la peculiar perspectiva maeztiana, sino también para perfilar mejor el periodo de transición ideológica entre el primer Maeztu y el de su etapa tradicionalista posterior. Asimismo, desde el examen de estos textos se atisba cómo se fue gestando inicialmente su idea de la «hispanidad» a partir de ideas previas como la de «integración del alma hispánica», conceptos que desembocarán años más tarde en el diseño ideológico de la revista Acción Española, explícitamente inspirada en el «integralismo lusitano», que conoció durante su periodo de transición.

\section{Palabras clave: Maeztu; Portugal; República; Iberismo; Hispani- dad; Análisis Político.}

* Este artículo se ha realizado en el contexto de una estancia de investigación en la Facultad de Letras y en el Centro de Estudos Interdisciplinares do Século XX (CEIS20) de la Universidad de Coimbra. Agradezco a la catedrática Maria Tavares Ribeiro, directora del CEIS20, su amable ayuda y orientación durante mi estancia en dicho centro. También agradezco las correcciones y sugerencias del catedrático José Luis Varela. A su vez, el trabajo forma parte del proyecto de investigación titulado: «Los discursos geopolíticos de la Península Ibérica durante las dictaduras de Salazar y Franco: proyectos y realidades de la alianza peninsular y su proyección internacional», aprobado por el Ministerio de Economía y Competividad (ref. HAR2015-68492-P) y dirigido por Juan Carlos Jiménez Redondo. 
Maeztu and Portugal. Political and Intellectual Analysis about the First Republic (1910-1926)

ABSTRACT: In this article, the author develop a compilation and analysis of the works that Maeztu made about Portugal between 1910 and 1926; years that fit with the rise and fall of First Portuguese Republic (1910's chronicles; his "Letters from Portugal» and others similar works). For its examination, developed throughout a contextual methodology, the article focuses on the two main topics of these essays: political and cultural issues. This analysis is particularly relevant in order to a better understanding of that peculiar ideological transition in the Maeztu's thought which come about between his first radical period and his late traditionalist period. Likewise, from the analysis of these texts, it can be better known how his wellknown concept of "Hispanity" was born from earlier considerations about the "integration of the Hispanic soul». All this previous ideas also influenced the creation of Acción Española, according to its roots in the "Lusitanian integralism», which he knew during his transition period.

Key WORds: Maeztu; Portugal; Republic; Iberism; Hispanity; Political Analysis.

\section{Maeztu y Portugal, Planteamiento de una Relación intelectual}

La relación intelectual de Maeztu con Portugal apenas ha sido estudiada aunque se trata de un autor que bien podría figurar en la nómina de lusófilos españoles del XIX y XX, en la que caben autores como Valera, Valle Inclán, o Unamuno ${ }^{1}$. Por otro lado, dentro de la cuestión del «iberismo», tan discutida desde ambos lados de la frontera peninsular, la actitud de Maeztu merecería igualmente la atención por parte de sus estudiosos, aunque el vitoriano siempre se manifestara reacio a la fusión iberista como modelo de integración luso-española.

Para estudiar la relación de Maeztu con Portugal habría que comenzar distinguiendo los dos importantes periodos que fraccionan su pensamiento: el del Maeztu progresista y liberal-socialista de sus primeros años y el del Maeztu tradicionalista y monárquico. Como es bien sabido, estas dos actitudes contrapuestas fueron mediadas por una etapa de transición ideológica cuyos contornos son difuminados y borrosos ${ }^{2}$ y que además ha sido eclipsada por la del primer Maeztu, pero especialmente por el Maeztu tradicionalista.

1 Sobre este tema, puede verse, respectivamente: DECOSTER, 33 (Madrid, 1956). GARCÍA MOREJÓN, 1964. ENGLEKIRK 42/1 (Madrid, 1959). ROCHA RELVAS 32/3 (Madrid, 2007).

2 Uno de los principales biógrafos de Maeztu, Vicente Marrero, estableció en su ya clásico Maeztu, una división en tres etapas del pensamiento de Maeztu, que, con resonancia dantesca, denominó: «infierno» (1897-1905), «purgatorio» (1905-1916) y «paraíso» (1916-1936). 
En este artículo se realiza un estudio contextualizado de los análisis políticos que un primer Maeztu en transición hacia el segundo realizó sobre la I República portuguesa, un periodo que historiográficamente también ha sido notablemente eclipsado por la etapa del «Estado Novo», como han señalado M. Baiôa, y P. Fernandes ${ }^{3}$. El presente estudio se basa en los artículos que Maeztu hizo, primero, para el diario Heraldo de Madrid en 1910 y después en una serie de artículos para El Sol, bautizados como "Cartas de Portugal» (1922-1923); asimismo, se analizan otros artículos y conferencias dentro de este periodo (1922-1926) donde Maeztu vuelve sobre la cuestión ${ }^{4}$. Este conjunto de artículos y discursos clarifican el inicio y creciente interés que manifestó Maeztu hacia Portugal y que tan claramente influiría algunos años más tarde en su concepción de la «hispanidad», así como en el desarrollo ideológico de la revista Acción Española, ya en su etapa tradicionalista 5 .

El objetivo del presente trabajo es, por tanto, analizar el interés que el Maeztu de sus primeras dos etapas manifestó hacia Portugal; cuestión que se centró en dos aspectos diferenciados pero conexos: 1) la preocupación por la (inestable) realidad política lusa derivada del advenimiento de la I República, y, 2) los aspectos centrales de la identidad cultural portuguesa con una especial atención a la necesidad de una integración luso-española de base cultural, pero no política. Respecto al primer aspecto, la inicial postura favorable a los ideales republicanos marcará la orientación de sus análisis, aunque sufrirá una profunda alteración cuando Maeztu se adentre en su etapa tradicionalista. Mientras que en el aspecto cultural, la variación ideológica respecto al último Maeztu será mucho menor, salvo en los elementos historiográfico-políticos, los cuales sufrirán una profunda revisión en su etapa tradicionalista.

\section{Dos CRÓNICAS DE MAEZTU SOBRe LA REVOLUCIÓN PORTUGUESA DE 1910}

El primer acercamiento intelectual de Maeztu hacia Portugal se produjo en dos artículos para el Heraldo de Madrid sobre la revolución portuguesa que estalló el 5 de octubre de 1910 y que acabó con la monarquía lusa, instaurando la Primera República de Portugal. Los artículos fueron escritos entre el 8 y

\footnotetext{
MARRERO, 1955, 367 y ss. Otra destacada y más reciente biografía es la de P. G. CUEVAS, 2003.

3 BAIÔA y FERNANDES, 2004: 29.

4 Parte de los textos analizados en este artículo estaba previsto que integraran el volumen XXX de las «Obras completas» de Maeztu que planificó Dionisio Gamallos Fierros y que nunca llegó a publicarse y cuyo título iba a ser precisamente Cartas de Portugal. GAMALLO FIERROS, 1953, s.p. Aunque el listado de Fierros es incompleto y contiene varios errores.

5 Para un análisis de la influencia integralista lusitana sobre el Maeztu tradicionalista, véase: P. SÁNCHEZ GARRIDO, 2014: 203-227.
} 
el 11 de octubre 1910 — con el estallido revolucionario todavía en curso-, y se enviaron desde Londres, por lo que se encuentran en los primeros años de su estancia londinense.

$\mathrm{Su}$ traslado a Londres se había producido en 1905, para trabajar inicialmente como corresponsal de La correspondencia de España. Pero las dos crónicas lusas que aquí examinamos no fueron publicadas en dicho periódico sino en el Heraldo de Madrid, para el que inició su etapa de colaboración en diciembre de 1909. Como ha señalado José Luis Villacañas, Heraldo de Madrid intentó aglutinar a liberales y socialistas en un frente antimaurista, línea que Maeztu articuló ideológicamente en su artículo «El liberalismo socialista», pero sin abandonar su inicial costismo noventayochista ${ }^{6}$.

Aunque durante su estancia londinense como corresponsal y cronista político se va a iniciar, ciertamente, su primera mutación ideológica, lo cierto es que en 1910 todavía era un autor netamente progresista, en una variante liberal-socialista que le hacía admirador del anarquista Kropotkin — de quien también se hizo amigo allí-, y de otros pensadores socialistas y liberales. Pero si seguimos la periodización clásica de Marrero, en el año 1910 estaríamos ya ante el segundo Maeztu, el de transición o «purgatorio». Sin embargo, a nuestro juicio es muy importante tener en cuenta que ambos artículos se encuentran en los años previos al crucial punto de inflexión ideológica iniciado en 1913, puesto que cuando Marrero señaló 1905 como inicio de su periodo de transición estaba tomando como referencia el hecho, relativamente fortuito, de su traslado a Londres - motivado por una reyerta con un periodista-, y no tanto algún hecho de relevancia intelectual en el pensamiento de Maeztu ${ }^{7}$. Por tanto, al tomar su traslado a Londres como hito inicial de su «purgatorio» ideológico se corre quizá el riesgo de confundir la causa (el cambio de contexto intelectual derivado del viaje a Londres) con el efecto (su posterior viraje ideológico). Por ello, una de las principales variables intelectuales para evaluar dicha inflexión, junto a las ideas fabianas y guildistas, es el abandono de su anticlericalismo inicial en aras de una creciente valoración ética e intelectual de lo religioso. En este cambio le influyen diversos intelectuales británicos, fundamentalmente T. E. Hulme, y otros, como el barón von Hügel — quien le mueve a ingresar en la London Society for the Study

6 VILLACAÑAS, 2000: 140-142, donde afirma: «De hecho, en todos estos artículos de El Heraldo de Madrid, los supuestos de Maeztu era los de Costa y, de forma consiguiente, los de la propia protesta del $98 »$,

7 Sin embargo, 1913 parece que sí fue decisivo para Maeztu en su proceso de cambio ideológico, según él mismo señaló, Cfr. MARRERO, 1955: 367; Villacañas relaciona este año con el inicio de «la gran transformación» de Maeztu, VILLACAÑAS, 2000: 160. Además, en 1913 inicia su colaboración en la revista fabiana The New Age, en cuyo contexto conoció a los intelectuales que propiciaron dicho cambio. 
of Religion -, así como R. H. Tawney, H. Belloc, o el reverendo R. J. Campbell, a quien califica de «teólogo socialista» ${ }^{8}$.

Pero, centrándonos en estas dos crónicas sobre la revolución, la primera de ellas, «Los acreedores de la Revolución» fue publicada en Heraldo de Madrid el 12 de octubre de 1910; aunque Maeztu la envió el día 8 desde Londres, tan solo tres días después de que estallara la revolución portuguesa. En este artículo y en el siguiente, Maeztu parte del recelo y hostilidad con la que fue recibida esta revolución desde la prensa inglesa, especialmente desde la más conservadora - percibiendo su máxima virulencia en el Saturday Review-, actitud conservadora de la que Maeztu se desmarca ${ }^{9}$. Las invectivas inglesas que analiza Maeztu parecen estar dirigidas, por un lado, contra ciertos aspectos estético-propagandísticos del proceso revolucionario, como las grandilocuencias retóricas de sus líderes ${ }^{10}$, o contra el trasfondo de «sebastianismo» ${ }^{11}$ que Maeztu advierte en ciertas arengas revolucionarias de Braga, como las que apelaban a una nueva concordia popular inspirada en un «deseo de grandeza». Pero lo que centra principalmente el interés de Maeztu en este primer artículo, más allá de ciertas especulaciones sobre los países que han podido financiar internacionalmente a los revolucionarios ${ }^{12}$; es la cuestión de cómo podría afectar al reconocimiento británico del nuevo régimen la incertidumbre de los británicos sobre los intereses económicos en Portugal. Maeztu concluye que en esa cautelosa suspicacia de la prensa y de los analistas ingleses no hay que buscar razones de maquiavelismo geopolítico, sino un mero cálculo conservador por parte de una sociedad y un gobierno que, como prudentes acreedores e inversores, contemplan con temor las imprevisibles veleidades revolucionarias del país vecino. Un temor, por otro lado, bastante «natural» en un país monárquico y conservador hacia el viraje republicano y revolucionario de otro país de la Vieja Europa con el que además tuvo el grave conflicto de $1890^{13}$. Como ha señalado Hipólito de la Torre:

8 Varios de ellos orbitaban en The New Age.

$9 \mathrm{Su}$ actitud anticonservadora es patente, como revela, por ejemplo, el detalle de su apostilla final: «Además, la prensa conservadora de Inglaterra se ha mostrado tan hostil o más hostil al nuevo régimen portugués que la alemana de la misma orientación o desorientación política». MAEZTU, 12.X.1910, p. 1, la cursiva es mía.

10 En frases como la de Teófilo Braga: «iCiudadanos! Sea este momento el comienzo de una época de moralidad austera y de justicia inmaculada».

11 El «sebastianismo», mitologema político arraigado en la conciencia popular portuguesa, a través de sus diversas reelaboraciones anhela el simbólico regreso del rey don Sebastián, como paradigma regenerador de la antigua grandeza nacional perdida. Sobre su evolución política: Cfr. SERRÃ̃, 1970.

12 Mientras que el Saturday review alude al apoyo desde Hispanoamérica, Maeztu parece decantarse por la ayuda alemana. Para el tema de los apoyos externos a la revolución, véase: MARTÍNEZ, 2001: 8 y ss.

13 Curiosamente, Maeztu no hace referencia al ultimátum. 
La República portuguesa tuvo que contar desde el primer momento con un ambiente internacional poco propicio para el desarrollo de su política externa. Portugal, gobernado por los responsables morales del regicidio, por los autores de una revolución que había dado al traste con el último monarca, caminaba bajo el signo del radicalismo en una Europa cuajada de cabezas coronadas ${ }^{14}$.

A ello hay que añadir que Inglaterra fue el lugar donde se exilió don Manuel, donde contó con la simpatía de la familia real inglesa y de los sectores conservadores. La sostenibilidad de la República dependía en buena medida del modo en que los gobiernos europeos, principalmente el británico y el español, vieran peligrar su estabilidad monárquica o sus intereses económicos, motivo por el que un sector de los conspiradores monárquicos exiliados desde Portugal puso sus esperanzas en que dicha oposición exterior acabase precipitando una intervención extranjera restauracionista ${ }^{15}$.

En su segundo artículo, publicado cuatro días después del anterior ${ }^{16}$, aunque «asegurada ya la República en Portugal [...]», Maeztu se introduce en cuestiones de mayor calado ideológico, revelando a un tiempo, su propia actitud intelectual. Así, bajo el título «Aspectos de la revolución» y manteniendo la perspectiva de la recepción exterior de la revolución por la sociedad británica, Maeztu aborda los que considera los tres principales rasgos de dicha revolución, entreverando su propia valoración. En primer lugar, vuelve sobre los llamamientos patrióticos de los líderes revolucionarios para recuperar la antigua "grandeza» perdida, que son vistos con cierta ironía por los británicos, pero que Maeztu disecciona con mayor profundidad. Nuevamente parece interpretarlos como una variante de lo que podríamos llamar, a pesar de su paradoja termiológica: sebastianismo republicano. Pero se observa que en estas arengas nostálgicas de grandeza resuena aquel lamento por la gloria nacional perdida que ya venían entonando años atrás influyentes intelectuales republicanos, como Eça de Queiroz, Anthero de Quental o T. Braga, unidos en la Questão Coimbrã, o en las célebres «Conferências do Casino». Desde esta especie de romanticismo republicano, dichos intelectuales lograron conjurar parcialmente la atonía reinante, a la par que alimentaron una mística republicana que acabaría triunfando en 1910. Sin olvidar relevantes acontecimientos previos, como el frustrado conato revolucionario de 1891 derivado del ultimá-

14 TORRE (1983): 30 y ss.

15 Para un análisis de la ambigua reacción británica hacia la república portuguesa, véase: TORRE, 1983, 191 y ss. Para el tema de las reacciones europeas ante la proclamación de la I República, véase: MARTÍNEZ, 2001, 24 y ss.

16 «Portugal. Aspectos de la revolución», Heraldo de Madrid, 16.X.1910, 1. Pero está firmado con fecha del día 11.X.1910. En su relación sobre los textos «portugueses» de Maeztu, Gamallo Fierros señala erróneamente que el artículo de esta fecha tiene como tema: «Letras de Portugal»; asimismo no menciona el anterior artículo. 
tum británico de 1890 — similar mutatis mutandis al Desastre español del 98 — ${ }^{17}$, o el regicidio en 1908 del rey Carlos y de su heredero ${ }^{18}$. Para un autor como Maeztu, miembro del 98, la situación intelectual generada ante este desánimo y humillación por la grandeza nacional perdida debió de resultarle muy familiar. Sin embargo, este llamamiento revolucionario a recuperar la grandeza lusa le suena a Maeztu más superficial y material que interior y espiritual, pese a la ascética (post)revolucionaria predicada por Teófilo Braga. Para el vitoriano, el republicanismo luso estaba aún demasiado contaminado por la envidia material respecto a sus prósperos vecinos europeos, por lo que considera de mayor pureza espiritual al republicanismo español. Pese a los paralelismos que observa entre el elemento republicano español y el portugués, la cuestión del iberismo brilla por su ausencia, al contrario que, por ejemplo, en Quental ${ }^{19}$.

Otro «aspecto» que destaca Maeztu es el decisivo del apoyo a la revolución desde las clases medias. Demasiado reacias hasta entonces a los posibles desmanes de la hybris revolucionaria, considera que han sufrido un cambio de actitud debido al hartazgo por los escándalos financieros del rey - y por lo que Guerra Junqueiro denomina «tiranía de corral»-, y por el prestigio social de líderes revolucionarios como Braga o Machado.

Pero al «aspecto» revolucionario al que dedica una especial atención Maeztu es al anticlericalismo revolucionario, pues según afirma: «[...] el carácter popular del republicanismo portugués estriba en su anclericalismo»; un anticlericalismo que para Maeztu explica buena parte del triunfo de esta revolución, pero que también parece compartir y celebrar internamente como parte de una «revolución cultural» necesaria para el nuevo régimen ${ }^{20}$. Nuevamente, toma como punto de partida el estupor del observador británico medio ante la hostilidad anticlerical de la revolución portuguesa, pero intenta disiparlo recurriendo a un análisis comparado a tres bandas entre el caso portugués, español, e inglés:

Los periódicos ingleses no aciertan a explicarse la hostilidad a los conventos que muestran los pueblos de Portugal y España (...). Los ingleses no pueden darse cuenta de lo que representan en la vida de la península ibérica sus ciento cincuenta

17 La humillación por el ultimátum británico impactó fuertemente en Portugal, motivando la letra de su himno nacional (A Portuguesa) y alimentando los argumentos republicanos que desembocaron en el 5 de octubre de 1910.

18 Sobre este contexto de la «República Vieja», véase: CAMPOS, 1998: 61 y ss; VALENTE, 1997.

19 Aunque en 1910 la preocupación por el iberismo estaba en decadencia. Sobre el paralelismo intelectual entre el republicanismo español y portugués y la cuestiones del iberismo y la revolución, véase: REIS, 2014.

20 Para el concepto de «revolución cultural» aplicado a la I República, véase CATROGA 2010: 96-101. 
o doscientos mil monjes de ambos sexos; otras tantas familias dilaceradas; otras tantas energías perdidas para el mundo; otros tantos soldados en guerra permanente contra la cultura, contra la riqueza y contra la vida civil; otras tantas máquinas que sorben, hasta agotarlas, las energías nacionales, siembran la disensión en los hogares, separan las mujeres de los hombres, los hijos de los padres, los comerciantes e industriales de sus clientes y los obreros de su trabajo ${ }^{21}$.

Maeztu desarrolla una apología del anticlericalismo luso recurriendo al curioso razonamiento que, según afirma, le hizo personalmente «un gran jurisconsulto inglés» —-seguramente, Percy Bunting22 - en el que este acusaba a célebres católicos españoles de haber perjudicado indirectamente a la Iglesia de Roma a lo largo de la historia. Se refería a santo Domingo de Guzmán con la Inquisición -, a los Borgia - justificando moralmente la Reforma de Lutero-, a san Ignacio de Loyola - al impedir la reconciliación con los protestantes-, y a Merry del Val — por entonces Secretario de Estado del Papa Pío X, paladín del antimodernismo- . Concluye Maeztu asumiendo este argumento y exclamando: «Pues si así fueron para con Roma, que está lejos, ¡calcule usted cómo serán para los que están cerca!». La posición ideológica del vitoriano por estos años queda aquí vivamente retratada, revelando unas ideas que están mucho más cerca del «iAbajo los jesuitas!» de su primera etapa que del acercamiento a la religión que experimentaría a partir de 1913.

\section{Las Cartas de Portugal en El Sol (1922-1923)}

El primer acercamiento intelectual de Maeztu a Portugal se produjo en las anteriormente referidas crónicas sobre la «República vieja» en 1910 para el Heraldo de Madrid, aunque fueron escritas desde Londres. Pero más relevante, cuantitativa y cualitativamente, será su segundo acercamiento, cuando una década más tarde y ya de regreso en España, fue corresponsal de El Sol y publicó en este conocido diario, tan vinculado a Ortega, una serie de once Cartas de Portugal. Una serie a la que él dio comienzo y que después fue conti-

21 R. de Maeztu, «Portugal. Aspectos...», 1.

22 Maeztu no revela su nombre pero señala que este «jurisconsulto» iba a representar a Gran Bretaña en el siguiente congreso internacional en Madrid sobre trata de blancas unos días después. En este congreso, los representantes británicos fueron: Claud Rusell, primer secretario de Embajada, y «Mr. Bullock», «director de la Oficina central de represión»; la presidencia de honor británica fue para el arzobispo de Canterbury y Sir Percy Bunting. Cfr. La correspondencia de España, 26.X.1910, pp. 4-5. Por tanto, seguramente se refería a Bunting (1836-1911), ya que este reformista social fue editor de la Contempororary Review y mantuvo cierta relación con los Webb y con otros intelectuales británicos de la órbita de Maeztu por entonces. 
nuada por destacados intelectuales, como Luis de Araquistáin o José Díaz Fernández ${ }^{23}$.

El periodo concreto de publicación de estas «Cartas de Portugal» de Maeztu, se extiende entre febrero de 1922 y enero de 1923, firmando Maeztu las ocho primeras desde Lisboa y las tres últimas desde Monte Estoril24. Estas «Cartas» fueron las siguientes: «El genio de Lisboa» (1.II.1922); «Las elecciones generales» (2.II.1922); «El gobierno de los demócratas» (9.II.1922); «La 'Seara Nova'» (10.II.1922); "Sensibilidad y heroísmo, o Portugal y Castilla» ${ }^{25}$ (15.II.1922); «Pesimismo, integralismo y republicanismo» (17.II.1922); «Los moderados: Vasconcellos y Barros Queiroz» (24.II.1922); «El problema militar: sables y rumores» (26.II.1922); «El valor de los escudos» (19.III.1922); «El hombre y la casa» (31.XII.1922); «La epopeya de Camoens» (9.I.1923); y «Anthero de Quental» (16.I.1923).

En cuanto a su contenido, aunque en varios de estos artículos se entremezclan los elementos, políticos, sociológicos, económicos, culturales y religiosos en diversas dosis, en buena medida, estas «cartas» podrían clasificarse en dos grupos: las cartas de análisis político y las de análisis cultural. En el primer bloque, el del análisis político $-\mathrm{y}$ social-, podemos englobar los siguientes artículos: «El genio de Lisboa», «Las elecciones generales», «El gobierno de los demócratas», «El problema militar: sables y rumores», «El valor de los escudos» y «Los moderados: Vasconcellos y Barros Queiroz». El resto de estas «cartas de Portugal», tienen, ciertamente, una temática más cultural y ensayística, como analizaré más adelante.

Pero en la relación entre Maeztu y Portugal, que en esta serie de artículos en $\mathrm{El} \mathrm{Sol}$ se torna ya directa y presencial, hay un hecho de gran relevancia, anterior a ella, pues un año antes, hacia 1920 o 1921, se produjo su contacto personal con Antonio Sardinha, el líder del «integralismo lusitano» y a quien podríamos considerar, una vez consumada su mutación ideológica tradicionalista, como su alter ego portugués. La cantidad de coincidencias y paralelismos

23 Aparecieron casi todas en primera página. Cuando Maeztu terminó su contribución a la serie, continuó con otra decena de «Cartas de Portugal», Luis de Arisquistáin (julio-octubre de 1923), centrándose en el iberismo y en una crítica al integralismo lusitano y a su líder Sardinha. En el Archivo Sardinha, existe correspondencia con Arisquistain. Alejo Carrera también firma un par (11.I.1923 y 1924). Prosiguió la serie José Díaz Fernández (1929-1930) y Osorio Oliveira (1930-1931). Seguramente, la serie cesó cuando El Sol fue traspasado por Urgoiti a raíz de que Ortega y sus colaboradores abandonaran el periódico tras su polémico «Delenda est monarchia», en «El error Berenguer», ORTEGA Y GASSET, 1930: 1.

24 Maeztu viajó a Portugal como «enviado especial», como aparece en su segundo artículo. Aunque los de Estoril los hizo aprovechando un viaje voluntario.

25 Las anteriores cartas iban numeradas en romanos, pero esta no llevaba numeración, mientras que la carta del 17 de febrero llevaba el número 5 por error ya que correspondía a la del 15.II.1922; por este error quizá las siguientes dejaron de ir numeradas. 
entre Maeztu y Sardinha es realmente asombrosa, incluyendo la conversión religiosa y el viraje tradicionalista desde comienzos liberales y anticlericales ${ }^{26}$. El encuentro entre ambos se produjo durante el exilio de Sardinha en España, entre principios de 1920 y mayo de $1921^{27}$, época en la que Sardinha ya estaba plenamente «convertido» ideológicamente, aunque Maeztu aún estaba en transición y mantenía alguna amarra con el liberalismo, como demuestra el inicio de su colaboración para el $\mathrm{El} \mathrm{Sol}$ de Ortega y Gasset, con quien algunos años más tarde rompería su amistad e intensa relación intelectual ${ }^{28}$.

\section{Las Cartas de Portugal en SU ANÁlisis POLítico}

En este primer bloque de análisis político, sus crónicas están circunscritas a un periodo muy delimitado cronológicamente, el de febrero de 1922, puesto que estas fueron publicadas entre el 1 y el 24 de dicho mes. Un periodo que por su creciente inestabilidad y ataques opositores puede considerarse representativo de la última etapa de la I República que desembocaría en el golpe de estado de $1926^{29}$.

El suceso histórico que motiva estas crónicas políticas son las elecciones portuguesas del 29 de enero de 1922, tan sólo unos días antes de la primera «carta». En estas elecciones, posteriores al asesinato del presidente dimisionario Granjo y al gobierno de concentración liderado por Cunha Leal, ganó el Partido Republicano Portugués pero sin mayoría absoluta — con 71 escaños de 163- . Tras la negativa de Costa para formar gobierno, lo hizo Antonio Maria da Silva ${ }^{30}$, pactando con otras fuerzas minoritarias ${ }^{31}$. El contexto previo auguraba un estado de insalvable inestabilidad del régimen después de la re-

26 Para un análisis de este paralelismo, véase mi estudio SÁNCHEZ GARRIDO, 2014. Sobre la recepción española de Sardinha, véase el artículo «Sardinha en España», GONZÁLEZ CUEVAS, 1995.

27 En 1919 se produce el regreso de Maeztu a España tras su estancia en Inglaterra, estableciéndose primero en Barcelona y poco después en Madrid, hacia principios de 1920, época en la que tuvieron la oportunidad de conocerse y de iniciar un importante contacto intelectual, en ambas direcciones.

28 La ruptura con Ortega fue progresiva pero fue importante el fuerte apoyo de Maeztu a la dictadura de Primo de Rivera, iniciada en 1923. La salida de Maeztu de El Sol se produjo en 1927.

29 Es lo que CASTRO LEAL (2009) denomina tercera fase de la I República (1919-1926).

30 Antonio María da Silva (1872-1950), cuatro veces jefe del gobierno portugués. Esta ocasión fue la segunda, siendo jefe del gobierno entre el 6.II.1922 y el 15.X.1923. Fue también ministro de muy diversas carteras. Dirigente revolucionario de los carbonarios y Gran Maestre del Gran Oriente Lusitano, tuvo muy destacada participación en el advenimiento de la I República. Tras la retirada de Afonso Costa en 1919 le sucedió como líder del Partido Democrático.

31 BAIÔA, 2014, p. 6. 
ciente «noite sangrenta» (1921) y del eco de varias dictaduras previas, la de Pimenta de Castro (24.I.1915 a 14.V.1915) y la de Sidónio Pais (5.XII.1917 a 14.XII.1918), también asesinado. La situación incluía amenazas guerracivilistas, así como de rebeliones monárquicas e izquierdistas; sin olvidar el constante temor de «intervención externa» propiciada por los conspiradores monárquicos, exiliados principalmente en Inglaterra y España ${ }^{32}$. Dicho temor de una intervención desde España, materialización del secular «peligro español», se vive en este contexto de un modo especialmente intenso, con constantes rumores de conspiración referidos a Alfonso XIII y a Inglaterra contra la joven República portuguesa. A ojos de los republicanos portugueses, parte de la prensa española también estaba reactivando el «peligro español», tanto la conservadora, por sus invocaciones al «fantasma bolchevique», como la progresista de diarios como $E l$ Sol, por el posible «abrazo de oso» de un iberismo unionista que, a menudo es visto con recelo y magnificado desde el otro lado de la frontera ${ }^{33}$.

Pero el periodo en el que se escriben estas cartas es el de una «endémica intestabilidad gubernamental», en el decir de Hipólito de la Torre, aunque bajo la apariencia de continuidad que marcó el encadenamiento de los tres gobiernos del republicano Antonio María da Silva ${ }^{34}$. Téngase en cuenta que durante el periodo de la I República se sucedieron 45 gobiernos - varios de pocos días-, y que en la rebelión monárquica de Monsanto posterior al asesinato de Pais se llegó incluso a proclamar por breve tiempo la llamada «Monarquia do Norte» (19.I.1919), mientras en el resto de Portugal se mantenía la República. Este último hecho afectó muy especialmente al integralista Sardinha, como participante de la conspiración. Su fracaso provocó el exilio de Sardinha en España, del que nacerá su reconciliación ideológica con España y su conexión con los futuros líderes del tradicionalismo monárquico de Acción Española, Maeztu incluido. Puede observarse cómo se entrevera en este caso la historia política portuguesa con el decurso intelectual de nuestro autor...

Ante este contexto, comienza Maeztu esta serie de cartas portuguesas renegando de su fatum viajero, pero advirtiendo a la par de su necesidad para todo escritor español: «[...] para un escritor español debiera ser obligatorio el

32 Estos rumores de intervención provocaron, tres legislaturas antes, la dimisión del presidente Manuel Maria Coelho (1921).

33 Como ejemplo de lo primero, pueden destacarse el artículo en $A B C$ firmados por Llanos Torriglia ( $A B C, 2 . I I .1920)$; como ejemplo de lo segundo, la campaña de Félix Lorenzo en El Sol (cfr. TORRE, 1980) quien previamente había escrito sus impresiones sobre la república portuguesa en su obra Portugal. Cinco años de República. Impresiones de un periodista español, Madrid 1915.

34 TORRE, 1984: 94. M. Baioa coincide con este parecer, op. cit. p. 32. Oliviera Marques considera que lo que define los años 1922 y 1923 es el «cansancio político» de la República, alegrados por el logro aeronáutico del «Lusitania». 
conocimiento de toda la Península, y para conocer hay que viajar» ${ }^{35}$. Señala que para conocer en profundidad el hecho concreto de las elecciones portuguesas: "Yo he encontrado más fácil venirme a Portugal a averiguarlo, que dar desde Madrid con las señas de quien pudiera sacarme de mis dudas». En este sentido, considera esencial experimentar la realidad o contexto que se quiere narrar. Por ello, dedica buena parte de este artículo a exponer una metodología experimental que comienza por pasear la capital portuguesa, lo cual le permite captar la naturaleza ultramarina y centrífuga de este pueblo, por contraste con la capitalidad española, de mayor «recogimiento» interior y de naturaleza más centrípeta. Este primer artículo apenas contiene referencias políticas, salvando una alusión al mayor internacionalismo y hábito viajero de los líderes portugueses por contraposición a los españoles. El dato lo ejemplifica en Afonso Costa, una especie de Azaña portugués y líder del casi hegemónico y radical Partido Democrático — partido célebremente conocido por su antigua denominación de «Partido Republicano Portugués» (PRP) antes de la escisión de 191136 - y en Brito Camacho, líder del republicanismo moderado de la oposición y cofundador en 1919 del Partido Liberal Republicano, resultado de la fusión de su Partido Unionista con el Partido Evolucionista de António José de Almeida ${ }^{37}$. Pero del análisis comparado no deduce Maeztu la superioridad del modelo de extroversión portuguesa respecto del español, sino la relatividad del mismo respecto a la propia identidad y circunstancias histórico-políticas, matizada con la necesaria apertura a un conocimiento recíproco: «Que cada uno sea como es, siempre que fuere algo útil. Y aprendamos a conocemos mutuamente». Esta frase bien podría servir de epítome de la visión maeztiana sobre la relación luso-española, alcanzando incluso su etapa tradicionalista. Su ideal de relación es de unidad en la diversidad, pero sin llegar al fusionismo iberista del que abominará en su etapa tradicionalista, entre otros motivos por la raigambre masónico-liberal que, como Sardinha, le atribuye.

Después de hacer este boceto del «genio portugués» y de exponer la metodología de las «Cartas», en el siguiente artículo aborda uno de los temas más netamente políticos: «Las elecciones generales» ${ }^{38}$. Vuelve a recurrir a un aná-

35 «El genio de Lisboa», El Sol, 1.II.1922, p. 1.

36 Para un estudio sobre Costa, véase: MARQUES, 1975.

37 El líder de este Partido Liberal y primer ministro en 1921 sería posteriormente António Granjo, asesinado la «noche sangrienta». Para la primera fusión liberal, CASTRO LEAL, 2008: 80 .

38 MAEZTU, El Sol, 2.II.1922. En esta carta aparece junto a la firma: «Lisboa, enero de 1922», por lo que puede deducirse que fue escrita justo después de las elecciones del día 29 y antes de que se hiciera público el recuento, ya que adjunta un breve «post scriptum», nuevamente firmado, constatando el acierto electoral de los augurios a favor del «Partido Demócra- 
lisis político comparado, pero esta vez de tipo cronológico al superponer el pronóstico de los resultados electorales de estas elecciones de 1922 con los obtenidos en las cinco elecciones portuguesas previas, acaecidas entre $1911 \mathrm{y}$ 1921, como se detalla en el siguiente cuadro:

\begin{tabular}{|c|c|c|c|c|}
\hline $\begin{array}{c}\text { Elecciones de } \\
\text { diciembre } \\
1911\end{array}$ & $\begin{array}{c}\text { Elecciones de } \\
\text { julio 1915 }\end{array}$ & $\begin{array}{c}\text { Elecciones de } \\
\text { julio 1918 } \\
\text { (Sidonio Paes) }\end{array}$ & $\begin{array}{c}\text { Elecciones de } \\
\text { mayo de 1919 }\end{array}$ & $\begin{array}{c}\text { Elecciones de } \\
\text { julio de 1921 }\end{array}$ \\
\hline $\begin{array}{c}\text { Demócratas: } \\
92\end{array}$ & $\begin{array}{c}\text { Demócratas: } \\
135\end{array}$ & $\begin{array}{c}\text { Presidencialis- } \\
\text { tas:144 }\end{array}$ & $\begin{array}{c}\text { Demócratas: } \\
122\end{array}$ & $\begin{array}{c}\text { Demócratas: } \\
74\end{array}$ \\
\hline $\begin{array}{c}\text { Evolucionistas: } \\
57\end{array}$ & $\begin{array}{c}\text { Evolucionistas: } \\
46\end{array}$ & $\begin{array}{c}\text { Monárquicos: } \\
45\end{array}$ & Liberales: 50 & Disidentes: 4 \\
\hline Unionistas: 54 & Unionistas: 19 & Católicos: 5 & Católicos: 2 & Liberales: 105 \\
\hline $\begin{array}{c}\text { Independien- } \\
\text { tes: } 19\end{array}$ & $\begin{array}{c}\text { Independien- } \\
\text { tes: } 5\end{array}$ & $\begin{array}{c}\text { Independien- } \\
\text { tes: } 2\end{array}$ & $\begin{array}{c}\text { Independien- } \\
\text { tes: } 19\end{array}$ & $\begin{array}{c}\text { Independien- } \\
\text { tes: } 10\end{array}$ \\
\hline Socialistas: 2 & Socialistas: 7 & $\begin{array}{c}\text { Fuerzas vivas: } \\
24\end{array}$ & $\begin{array}{c}\text { Socialistas: } 8 \\
\text { Católicos: } 1\end{array}$ & $\begin{array}{c}\text { Reconstituyen- } \\
\text { tes: } 17\end{array}$ \\
\hline & Centristas: 2 & Populares: 15 & Católicos: 4 \\
\hline
\end{tabular}

FUENTE: Datos extraídos del artículo «Las elecciones generales», El Sol, 2.II.1922. Maeztu combina aquí los diputados y senadores de cada partido.

Según concluye Maeztu de su análisis, el Partido Demócrata de Afonso Costa venía siendo demasiado poderoso como para que pueda existir una alternancia, pero no lo suficientemente fuerte como para gobernar con solidez frente a una variada e intensa oposición, lo cual sume a Portugal en una permanente inestabilidad, salpicada de constantes revoluciones populares, conspiraciones monárquicas y rebeliones militares ${ }^{39}$. Además, ve a la sociedad portuguesa demasiado estratificada sociológicamente respecto a los distintos partidos, pues arguye que el partido republicano concita el apoyo de la admi-

ta» y la derrota del gobernante por el Partido Liberal Cunha Leal. Por tanto, fue escrita el 30 o 31 de enero de 1922.

39 La coincidencia con este juicio era algo común incluso en la propia época, como se puede ver en José Luciano, quien afirma que «La República no puede vivir ni con Alfonso Costa ni sin Alfonso Costa», en Guerra Junqueiro, o Cunha Leal para quien el Partido Democrático este es el «astro central» en torno del cual han de girar los otros partidos. PABÓN, 1945, 102. La casi identificación del partido de Costa con el régimen republicano y la escasa representatividad opositora provocó una crisis de legitimidad que agravó la progresiva inestabilidad republicana, BAIÔA, 2014, p. 2. 
nistración pública, de buena parte de los caciques y de las masas populares que apoyaron la revolución. Por otro lado, los monárquicos y republicanos moderados atraen el apoyo intelectual y de las clases adineradas, mientas que un proletariado aún emergente se debate entre socialistas, comunistas o sindicalistas. Sin olvidar a un ejército bastante inestable, igualmente, cuyos oficiales se reparten entre los diversos partidos. No obstante, señala Maeztu que desde el régimen se va abriendo paso una «voluntad de poner fin a las violencias revolucionarias» y que se busca una política de mantenimiento del orden. Maeztu considera fundamental asegurar el orden y la paz principalmente en dos sectores: el republicanismo popular y el ejército, que efectivamente serán los principales protagonistas del agitado decurso político portugués durante buena parte del siglo XX. No obstante, la relación ejército-República irá entrando en una tensión cada vez más crítica a partir de 1924.

En el siguiente artículo, «El Gobierno de los Demócratas», Maeztu mantiene su atención centrada sobre el Partido Democrático que acaba de ganar las elecciones y que está a punto de tomar el poder en coalición con otros partidos minoritarios ${ }^{40}$. Sin embargo, este artículo es en realidad una entrevista a uno de los más destacados políticos del Partido Democrático Republicano, junto a Afonso Costa — que se negó a formar gobierno-; se trata del carismático Antonio María da Silva. En cuestión de días Silva sería primer ministro en el mandato de mayor permanencia de toda la I República y ya en 1925 sería el último gobernante de la Primera República de Portugal, antes del golpe militar de mayo de 1926. En su entrevista, Maeztu apenas interviene, solamente introduce una primera pregunta sobre la voluntad de conformar gobierno por parte de los republicanos y otra sobre el rumor que había prendido en España e Inglaterra de que la revolución portuguesa pudiera acabar derivando en una revolución bolchevique, cuestión que Silva niega tajantemente. El resto del artículo es un cuidadoso «mitin» por parte de este político republicano, que además se adelanta a señalar la buena relación con la monarquía española ${ }^{41}$. En su respuesta, da Silva marcaba las distancias republicanas para con los revolucionarios «octubristas» que protagonizaron la «noite sangrenta $»^{42}$, como también frente a la excesiva intervención de los militares en la

40 MAEZTU, 9.II.1922. Estos fueron: independientes, católicos y regionalistas. Cfr. BAIÔA, 2014: 6.

41 La única idea propia que vierte Maeztu, tras augurar la inminente conformación del gobierno republicano, es su utópico anhelo de «que llegue el día afortunado en que los pueblos mismos sepan expresar y hacer cumplir su voluntad sin necesidad de que los hombres públicos les guíen».

42 La revolución del 19 de octubre de 1919 se saldó con la dimisión del gobierno republicano liberal de Granjo y con una cruenta matanza, en esa noche, de líderes republicanos moderados, como el propio António Granjo, y algunos otros padres republicanos, como Manuel da Maia, o Machado Santos. 
política nacional. De hecho, el «problema militar» portugués será analizado monográficamente por Maeztu en el artículo posterior ${ }^{43}$, donde considera necesario contener el excesivo poder de los militares - «custodiar a los custodios»-, aunque sean estos republicanos, para que así la República no quede prisionera de su propia guardia. Se trata de un problema que, según Maeztu, no es exclusivo de Portugal.

Otra de las preocupaciones sobre las que vuelve constantemente Maeztu es el peligro que encierran los «conspiradores monárquicos», a los que acusa de poner constantemente en peligro la estabilidad del país para obtener ventajas para la causa monárquica. Frente a ello Maeztu toma nota de la aspiración republicana de Silva por erigir al PRP en un partido auténticamente «nacional» - quizá en respuesta al Partido Republicano Nacionalista que se gestaba desde la oposición-, motivo por el que este se jacta de haber «amnistiado una vez y otra a los conspiradores monárquicos» pese al hartazgo que según da Silva estos provocaban con sus constantes «agitaciones»e «ingratitud».

En el artículo del 23 de enero de 1923 titulado «Los dioses crueles» - perteneciente a la serie «Pareceres»-, Maeztu denuncia nuevamente la responsabilidad de los conspiradores monárquicos al expandir falsos rumores de revolución y terrorismo en contra de la paz interna y del prestigio externo del país. Frente a esta actitud, se muestra muy tajante Maeztu en su condena de este elemento conspirador, ya que: «En el altar de su Moloch, que es la Monarquía portuguesa, está inmolando a su país propio» ${ }^{44}$. Pero en él apunta también una crítica vigorosa contra la «bandera roja», «recientemente» alzada desde Moscú, y contra la dictadura del proletariado, que se han erigido en el lugar de un dios: "Ya no se cree en un Dios universal. Se cree en el partido, en la patria, en la clase social. Y no se advierte que los dioses parciales son necesariamente dioses crueles, porque, por de pronto, no es uno, sino el otro, quien sufre la crueldad».

Antes de hacer otras destacadas entrevistas, Maeztu dedicó otro artículo a un tema más centrado en la política económica: «El valor de los escudos», centrado en la fuerte devaluación del escudo y en sus posibles soluciones ${ }^{45}$. Parece este artículo más bien una preparación o contextualización del siguiente artículo-entrevista, dedicado a la oposición y titulado «Los moderados: Vasconcellos y Barros Queiroz». En este, Maeztu hizo otras dos entrevistas a

43 MAEZTU, «El problema militar: sables y rumores», 26.II.1923.

44 Más adelante añade: «Por amor a un partido político se sacrifica el país. Este es el caso de los monárquicos portugueses que inventan explosiones en Lisboa para servir su causa», MAEZTU, «Los dioses crueles» 23.I.1923.

45 «El valor de los escudos» El Sol 19.III.1922. Más allá de la cuestión en sí, lo que le llama la atención es que los problemas económicos son un asunto ampliamente discutido en los periódicos portugueses y que es seguido por la población, al contrario de lo que ocurría en España, cuyas noticias económicas aun eran muy escasas. 
destacados líderes portugueses del republicanismo en la oposición, aunque habían sido presidentes anteriormente: Augusto de Vasconcelos ${ }^{46}$ —entonces líder en el Senado_- y Tomé José Barros Queiroz ${ }^{47}$ - líder en el Parlamento-. Maeztu intercala en el mismo artículo estas dos entrevistas para abordar a partir de ellas las principales cuestiones políticas y económicas que atraviesa el país. Ambos políticos arguyen que la crisis e inestabilidad políticas del país están motivadas fundamentalmente por la crisis económica, que es internacional y provocada por una ausencia de préstamos externos, por lo que consideran que se trata en realidad de una crisis artificial de índole crediticia internacional. Cuando Maeztu sugiere la posibilidad contraria, es decir, el que dicha crisis económica y la ausencia de préstamos a Portugal fuera debida a la inestabilidad y falta de consolidación política de la República, Barros Queiroz se muestra tajante en la idea de que el pueblo portugués es «ardorosamente» republicano. Ante la rebelión monárquica de Monsanto, según afirma, «hasta los viejos y los niños se armaron para que desapareciese todo peligro de una restauración monárquica». Pero, además, considera republicanos a la mayoría de los oficiales del Ejército, a los socialistas, a los sindicalistas y a los anarquistas. Sobre el problema militar, ambos políticos coinciden en señalar que es en el fondo un problema de malestar patriótico, que se resolverá cuando se atajen los problemas derivados de la crisis económica. De hecho, algún tiempo más tarde, Barros Queiroz intentó denodadamente mediar para que Estados Unidos concediera un crédito a Portugal por valor de 50 millones de dólares, lo cual fue anunciado por Afonso Costa como salvación económica de la República. Pero la negativa final de dicha concesión fue considerada como uno de los factores que contribuyó al descrédito de la I República, propiciando la inestabilidad previa al pronunciamiento militar del 26 de mayo de 1926 que acabó con la Primera República Portuguesa y que abrió paso a la secuencia de dictaduras militares que desembocaría en el «Estado Novo» de Salazar. El descrédito del Partido Republicano de Silva - acusado de caciquil, dictatorial...-, era generalizado y la conspiración golpista catalizó a todo el espectro opositor, de izquierda a derecha ${ }^{48}$.

En la redacción casi consecutiva de las diez Cartas de Portugal, se produce un lapso temporal de casi un año entre la Carta novena (febrero de 1922) y la

46 Augusto de Vasconcelos (1867-1951), fue diplomático, profesor de Medicina y político republicano del sector independiente, aunque próximo a B. Camacho. Ministro de Asuntos Exteriores varias veces, fue presidente entre el 13.XI.1911 y el 16.VI.1912. Embajador en Madrid entre 1914 y 1917.

47 Tomé Barros Queiroz (1872-1925), comerciante y político republicano. Llegó a ser ministro de finanzas y presidente del gobierno entre el 24 de mayo y el 30.VIII.1921. Para su biografía política, véase: Vasco de QUEIROZ, 1985.

48 BAIÔA, 2014: 8. 
décima (diciembre de 1922). Sin embargo, durante este transcurso de tiempo, Maeztu no abandonó por entero el tema portugués. De hecho, la prensa de la época da buena cuenta de la conferencia que impartió el 6 de marzo de 1922 en la Residencia de Estudiantes con el título «Portugal y su política». La segunda parte de esta conferencia fue otra conferencia titulada: «Portugal y su lírica», en el Ateneo de Madrid (13 de marzo de 1922). Ambas formaban parte de un ciclo de tres conferencias, siendo la tercera la del célebre poeta luso Eugenio de Castro ${ }^{49}$.

\section{HACIA LA GÉNESIS DE LA «HISPANIDAD» MAEZTIANA. El ANÁliSiS CULTU- RAl en las Cartas de Portugal}

En el segundo grupo de «Cartas de Portugal», que como se ha dicho tienen un tema más propiamente cultural y una naturaleza más ensayística que sus trabajos de crónica política, pueden distinguirse las siguientes: la Seara Nova, «Sensibilidad y heroísmo, o Portugal y Castilla», «Pesimismo, integralismo y republicanismo», «El hombre y la casa», «La epopeya de Camoens» y «Anthero de Quental». Dos de ellas tienen un tema complementario puesto que analizan dos movimientos intelectuales - contrapuestos ideológicamente-, apoyados en sendas revistas: la Seara Nova, movimiento y órgano de la intelectualidad progresista republicana, aunque con una filiación filo-liberal ${ }^{50}$; y el «integralismo lusitano» de la revista Naçao Portuguesa, como movimiento del tradicionalismo monárquico religioso. Por tanto, aunque son artículos de temática cultural contienen a su vez un intenso trasfondo político. En su artículo sobre la Seara Nova, vuelve a recurrir a una entrevista al principal representante de dicho movimiento: Jaime Cortesão ${ }^{51}$. Precisa Maeztu que por dos ve-

49 El 15 de marzo de 1922 participaba en un homenaje en el Palace a Eugenio de Castro, junto a una amplia representación intelectual, entre los que se contaban Eugenio D'Ors, Américo Castro, Pérez de Ayala, Jiménez Frau, etc. Presidió el acto el marqués de Quintanar, en el que quizá fuera uno de sus primeros encuentros con Maeztu. El Sol, 16.III.1922, 7. Maeztu volvía sobre el tema en su artículo: «Portugal, el amor y la lírica», Hermes, 1922, 77.

50 Seara Nova, fundada en octubre de 1921, tuvo como principales líderes a Raúl Proença, Jaime Cortesão y Câmara Reis. Como han señalado Antonio Reis y R. Ferna, estaba formada por «intelectuales políticos» - $\mathrm{u}$ «orgánicos», en el sentido gramsciano-, y buscaba coordinar a una élite intelectual republicana en torno a una estrategia liberal progresista que lograra superar la crisis permanente del régimen republicano, a la vez que contraatacar a su movimiento antagonista, el integralismo lusitano, y contrapesar a la izquierda radical. Aunque se decía suprapartidista, se movilizó en ciertas actuaciones, como en la promoción de un «Programa Mínimo de Salvação Pública» (Seara Nova, 12.IV.1922) con apoyo de la «União Cívica» (marzo 1923). A finales de 1925, frente a la creciente inestabilidad republicana y rumores golpistas apoyaron una dictadura de inspiración revolucionaria. A. REIS, 2003: 60-91; 2004: 325 y ss.

51 Jaime Cortesão (1884-1960), estudió letras y medicina en Coimbra, trabajó fundamentalmente en el mundo intelectual y literario, impulsando revistas como A Áquia, Renascença y 
ces éste le contestó a sus preguntas sobre la revista - órgano que entonces contaba tan solo con cuatro meses de existencia-, y a tenor de la descripción física tan vívida que hace de este intelectual, seguramente fue fruto de algún encuentro personal. En el desarrollo de este artículo-entrevista, Maeztu nuevamente vuelve a exponer las palabras del entrevistado, entremezclándolas con sus propias valoraciones, por lo que se complica mucho la labor de separar su propia visión de la expuesta por Cortesão, quien lógicamente se refiere a la revista en unos términos muy apologéticos ${ }^{52}$.

En cualquier caso, el movimiento searista es explicado en el artículo por contraste con el integralismo lusitano y con su concepto de la historia y de la tradición ${ }^{53}$. Pero, en la descripción posterior del integralismo, y que parece pertenecer al propio Maeztu, este sale peor parado, con apelativos como «oscurantismo entusiasta» y acusaciones de una búsqueda «antirracionalista»y «a ojos cerrados» de la tradición nacional, ya que según el artículo, estos defienden que: «(...) la inteligencia es meramente destructiva, mientras que la fe salva, que es lo que dicen los tradicionalistas españoles y los integralistas portugueSes ${ }^{54}$. Así, mientras que los integralistas ensalzan por sistema lo relativo a la tradición y a la fe, los searistas más bien criban de la tradición aquello que ha impulsado sus momentos creativos y «(...) se esfuerzan por ver la realidad a la luz implacable del sol, aunque acaso les guste más sentirla bajo la incertidumbre espectral y nocharniega de un pálido "luar" $\gg{ }^{55}$. Por eso, Maeztu le augura a la revista republicana una influencia nacional comparable, cuando menos, a la que ya estaba ejerciendo el integralismo en las filas tradicionalistas ${ }^{56}$.

En el artículo dedicado al integralismo — «Pesimismo, integralismo y republicanismo»-, comienza desmarcándose del pesimismo que los propios

Seara Nova. Apoyó la revolución que instauró la I República. Durante un tiempo ingresó en la masonería. Fue director de la Biblioteca Nacional en torno a la cual se organizó el grupo de Seara Nova. Cuando triunfó el golpe militar de mayo de 1926 se exilió en España, Francia y Brasil. Volvió al final de su vida a Portugal donde se le ofreció liderar la oposición política, cosa que no pudo asumir por su avanzada edad.

52 Se excusa Maeztu del siguiente modo: «Como no he logrado apoderarme de la medida exacta de lirismo, fuerza, saber, lógica, ironía, que constituye su personalidad, me veo reducido a traducir sus conceptos a palabras mías», "La "Seara Nova"», El Sol, 10.X.1922.

53 Para un análisis intelectual del movimiento, véanse los trabajos de CARVALHO, especialmente 2003: 137 y ss, donde analiza el desarrollo del movimiento desde 1913 en Alma Portuguesa. También, CRUZ, 1982: 137 y ss.

54 Nótese la crítica al tradicionalismo español que implica esta afirmación, que seguramente es propia de Maeztu.

55 «Luar» en portugués alude a la claridad propia de la luz de la luna como reflejo indirecto de la solar.

56 Algunos años después, en 1923, surgió una fugaz y curioso experimento editorial que prometía ser una conciliación o síntesis integradora de los movimientos integralista y seaeiro en la revista llamada Homens Livres. Para un análisis, véase: MEDINA, 1978. 
portugueses exhalan sobre su propio país, pero advierte que esa conciencia de la decadencia propia es claro signo «de su despertamiento, de su regeneración espiritual ${ }^{57}$. Este pesimismo regeneradoramente positivo Maeztu lo llama «pesimismo metódico», reconociéndolo en la Seara Nova. Sin embargo, considera que hay otro movimiento —el integralista - cuyo pesimismo no lleva a la regeneración interior sino a fiarlo todo a un «una revolución cósmica», a «un cambio de régimen», o a una «transformación externa» derivada de la adhesión a una idea, partido político o restauración dinástica. En su descripción sale nuevamente airosa la actitud searista, pero Maeztu se desmarca de las actitudes antagónicas que conjuran ambos movimientos: la del espíritu de restauración y vuelta al pasado del integralismo - que considera como una continuación del mito del sebastianismo luso-, y la del radical espíritu de renovación, propio del republicanismo popular. Pero en su conferencia coetánea «Portugal y su política», de marzo de 1922, diversifica más esta cuestión y caracteriza al «pombalismo» como la actitud revolucionario-popular de arrasar con el pasado. El término medio virtuoso parece insinuarlo Maeztu en el searismo, que en dicha conferencia identifica con el espíritu del infante D. Enrique -impulsor y promotor de las grandes epopeyas descubridoras del siglo XV luso-. Por tanto, frente al sebastianismo (integralista) y al pombalismo (revolucionario), es en este espíritu del infante Enrique — «la actitud más noble de la psicología portuguesa»_-, donde se inspiran, según Maeztu, los hombres de Seara Nova, y por ello confía en que ellos «acaben por repudiar todo humanismo para dedicarse a la mejora del hombre».

Por otro lado, la actitud tradicionalista consiste en recuperar el alma perdida de la nación a través de sus tradiciones e instituciones para que esta vuelva a ser lo que fue. Para Maeztu esta es la actitud básica de todo «credo tradicionalista», lo que cambia en los diversos países es la cuestión del respectivo candidato al trono que habría de protagonizar esa restauración. Pero, en la actitud antagónica del republicanismo popular, o del socialismo, del comunismo y del anarquismo - lo que no afecta necesariamente a Seara nova-, Maeztu, también ve lo que en el fondo no es sino otra variante inversa de la misma «fe ingenua» que los tradicionalismos fían en la salvación mediante un «cambio de régimen» ${ }^{58}$. La conclusión de Maeztu parece apostar por un auténtico realismo popular que despierte de estas ensoñaciones y que a través de ese pesimismo eficaz emprenda, a tientas, la ardua tarea de transformar los ensueños de restauración o renovación en una faena cotidiana de regeneración personal y social:

57 Cuando Luis de Araquistain prosiguió las «Cartas de Portugal» dirigió varias contra el integralismo lusitano (El Sol, 6.IX.1923 y 9.IX.1923).

58 Señala como prueba las últimas elecciones que han llevado al poder al Partido Democrático bajo las críticas a los republicanos moderados, que para muchos seguidores de Costa, autoconsiderados los «buenos republicanos», no son más que «monárquicos encubiertos». 
Los nombres cambian. Las cosas son las mismas. A la fe ingenua sucederán el pesimismo y el escepticismo, y en la desolación de las desolaciones fermentará la levadura que levantará de nuevo al pueblo. Sólo que estas cosas no suelen acontecer de un modo catastrófico, sino que poco a poco desilusión tras desengaño, los sueños de restauración y de renovación se van trocando en normas de la prosaica tarea cotidiana ${ }^{59}$.

Se ve en estas reflexiones cómo se ha ido alejando de sus antiguos ideales socialista-liberales ${ }^{60}$. Pero está aún alejado asimismo de su futura identificación con el tradicionalismo español, o de su futura convergencia con el integralismo lusitano de su par Sardinha, a quien ya había conocido personalmente durante su exilio español. Así, probablemente refleje este fragmento uno de los momentos más equidistantes y apolíneos del dionisiaco Maeztu, en el inicio de un año clave en su trayectoria ideológica, como fue el meridiano de 1923. Se percibe en esta serie de artículos un cierto distanciamiento suspicaz frente a ideologías o «humanismos» redentores a favor de una defensa del «hombre de a pie», del trabajador y ahorrador anónimo; una postura más cercana al regeneracionismo galdosiano ${ }^{61}$. Esta sensación más apolínea y anarquizante de habitar una cierta «tierra de nadie» intelectual, tuvo que ejercer un cierto atractivo para él, pero seguramente le fue difícil mantenerse en ella dada su propensión «dionisíaca» al apasionamiento intelectual.

Entre los tres artículos restantes de sus «Cartas de Portugal» y los siete anteriores media casi un año entero, ya que el último de los anteriores es de marzo de 1922 y el primero de estos tres está publicado el último día de ese mismo año. Además de su cronología también cambia su ubicación física, ya que esta vez los firma desde Monte Estoril. Por otro lado, así como en su viaje anterior a Portugal iba en calidad de «enviado especial» de $E l$ Sol, el motivo de este viaje es más bien personal: «He venido a una playa portuguesa para que un hijo mío tome unas semanas los aires de la mar. El año pasado

59 MAEZTU, «Pesimismo...», art. cit. 1923.

60 Esta actitud crítica hacia «bolchevismo», «socialismo» y «comunismo», sin confundirlos, también se percibe en la carta portuguesa: «El hombre y la casa», donde califica a los socialistas portugueses de ser nuevos burgueses y soñadores despiertos en cuanto adquieren su propia vivienda. Asimismo, la revolución no será más que una «ventolera política» que deja intacta la estructura política cuando estamos ante una «democracia de propietarios, como es esencialmente Portugal» y donde «se halla la riqueza distribuida con amplia normalidad». El único sueño realista para Maeztu es el de una sociedad donde se haga la «[...] propiedad asequible a todo hombre que quiera trabajar y sepa ahorrar, hasta que no se oigan otras quejas que las de los perezosos y los pródigos [...]», MAEZTU, «El hombre y la casa», El Sol 31.XII.1922 (1921). Esto recuerda a su modelo del español trabajador: el señor Raventós, en su Hacia otra España, Maeztu, 1899, 24.

61 En su obra sobre Maeztu, José Luis Villacañas, ha estudiado esta visión de Maeztu a lo largo de sus diversas etapas bajo la perspectiva del hombre de clase media y de la burguesía, véase, VILLACAÑAS, 2000: 86 y ss. 
principié a estudiar a Portugal desde un hotel de su capital. Este año sigo el curso desde una de sus playas» ${ }^{62}$. Quizá por ello el tono de estos artículos sea menos cercano a la crónica política «profesional» que al ensayo cultural tan personal de Maeztu.

En estos tres artículos, uno de ellos dedicado a Camoens, otro a Anthero de Quental y otro de crítica social costumbrista, Maeztu se aparta aún más del tema político y se sumerge en la búsqueda del alma portuguesa plasmada a través de su ethos cultural y social. Pero lo que anda buscando por debajo de ello, como nos revela en su carta «La epopeya de Camoens» (1923), es la «integración del alma hispánica», adelantándose a lo que será el planteamiento inicial de su influyente Defensa de la hispanidad ${ }^{63}$. En una carta a Sardinha de estas fechas, preconiza la actitud que ambos plasmarán posteriormente en sus respectivos ideales convergentes de «hispanidad» ${ }^{64}$ cuando apunta a una «integridad del alma» peninsular, es decir, a la necesidad de una integración de «la tradición cultural de Castilla con la de Portugal». Todo esto aparece claramente en una carta escrita por esta fecha a Sardinha:

Esta corta estancia en Estoril me ha servido hasta ahora para leer despacio Os Luisiadas y a Antero de Quental. Excuso decirle que no he perdido el tiempo. Cada vez estoy más persuadido de que es cierta mi adivinación de que la integridad del alma, para un peninsular, consiste en completar la tradición cultural de Castilla con la de Portugal, sin olvidar los elementos esenciales que aportamos al espíritu otros peninsulares que, como los vascongados, no habíamos influido hasta ahora esencialmente en la cultura, salvo en el caso accidental, pero muy significativo, de Lo-

62 MAEZTU, «El hombre y la casa», art. cit. 1922.

63 Casi nada más comenzar este libro, y su artículo previo en el primer número de Acción Española, afirma: «Primera cuestión: ¿se incluirán en ella Portugal y Brasil? A veces protestan los portugueses. No creo que los más cultos. Camoens los llama (Lusiadas, Canto I, estrof. XXXI): 'Huma gente fortissima de Espanha'. [...] Hispánicos son, pues, todos los pueblos que deben la civilización o el ser a los pueblos hispanos de la Península. Hispanidad es el concepto que a todos los abarca». MAEZTU, 2006: 15.

64 Maeztu en su Defensa de la hispanidad atribuye equivocadamente el concepto «hispanidad» al sacerdote Zacarías de Vizcarra, en un artículo de Buenos Aires en 1926. En realidad, el concepto «hispanidad» había sido propuesto en 1910 por Unamuno en el diario bonaerense La Nación, («Sobre la argentinidad», 11.III.1910), pero fue popularizado hacia 1926, entre otros, por Luis de Araquistain desde El Sol; por Vizcarra, desde Buenos Aires; o por el propio Unamuno, en su artículo «Hispanidad» (1927), donde apela a la «americanidad»e incluye Portugal. Para un análisis, véase la obra de J. César Chávez Unamuno y América, publicada en 1964. En el caso de Maeztu, la referida génesis de su ideal de integración del «alma hispánica», entendida como unión cultural luso-española, previa a su fase tradicionalista, muestra que se trataba de algo considerablemente más complejo que una «reaccionaria e incluso protofascista visión de Maeztu» enfrentada a la «hispanidad» unamuniana, según defiende ROBERTS, 2004, p. 78. 
yola. Que en lo político vaya cada uno de nuestros países por donde quiera, pero en lo espiritual hay una unidad que es salvadora para todos ${ }^{65}$.

Pero dicha integración es contraria a los unionismos políticos de corte iberista $^{66}$. Uno de los fundamentos para esta integración de las almas nacionales es el elemento cultural —en su etapa tradicionalista pondrá más acento en el religioso-, para lo cual toma como símbolo la unión entre el Quijote y las Lusiadas; entre el clásico nacional español y el equivalente portugués de Camoens. El análisis de Maeztu sobre las Lusiadas es un canto a las virtudes del poema, sobre todo por su peculiar imbricación entre lo épico y lo lírico en la narración de una gesta descubridora que deviene en alegórica recreación del espíritu portugués. Pero en una lectura más «política» del poema, Maeztu advierte que aunque una parte del poema está dedicada a evocar las luchas de Portugal contra León y Castilla, no contiene una visión hostil hacia estos pueblos hispánicos, por el contrario considera como obra común a todos ellos la de luchar contra el enemigo común árabe sobre la base de una «solidaridad cristiana». Asimismo, considera que para Camoens «Portugal es un miembro de Hispania, como ésta es un miembro de Europa y de la Cristiandad». Esa Hispania abarcante de Camoens conlleva una integración peninsular que no menoscaba la identidad de Portugal, ni aboca a un imperialismo español.

Por lo tanto, en este artículo adelanta y funde dos temas importantes en la obra de Maeztu, la del Quijote como símbolo cultural y nacional, y la aspiración hacia una integración luso-española bajo el ideal de la hispanidad ${ }^{67}$. Así, el Quijote, en su integración con las Lusiadas, nos permite captar la grandeza del alma hispánica como unión entre el genio dramático (castellano) y la inspiración lírica (portuguesa), a la vez que nos alcanza una comprensión más perfecta de ambos clásicos de la literatura. En su famoso ensayo sobre Don Quijote, don Juan y la Celestina (1926) - tres años posterior al artículo-, Maeztu afirma que donde acaban las Lusiadas, verdadera epopeya hispánica,

65 Carta de R. de Maeztu, 11.I. 1922 [posiblemente 1923], legajo 358, Archivo Sardinha, Universidad Católica de Portugal. Este fragmento es una reproducción tomada de GONZÁLEZ CUEVAS, 2003: 201, ya que en el referido Archivo, la carta correspondiente a esta referencia ya no existe. Por la referencia a su estancia en Estoril y por los datos sobre la lectura de Camoens y de Anthero de Quental es más plausible que la fecha de composición de la carta sea enero de 1923 y no 1922, ya que en su artículo «El hombre y la casa» reconoce que en dicha estancia de 1923 en Estoril ha leído estas dos obras. Por otro lado, su estancia portuguesa del enero anterior fue en Lisboa, no en Estoril.

66 En su conferencia en la Residencia de Estudiantes de marzo de 1922, afirmaba: «Dejemos a un lado el problema de la Unión Ibérica. No pensemos en tal cosa. Para el florecimiento de los dos países basta con conocernos a fondo y con trabajar unidos en pro de los mismos ideales», MAEZTU, «Portugal y su política» [fragmentos], $A B C$, 7.III.1922, p. 16.

67 Una similar comparativa Quijote-Lusiadas puede verse en Unamuno, cfr. GARCÍA MOREJÓN, 1964: 162. 
empieza el Quijote: «Sin las Lusiadas no se puede entender el libro de Cervantes. Entre una y otra obra media el curso de una generación. No está bien que se lea el Quijote sin las Lusiadas, ni viceversa. ¿A dónde se irá, pregunta, con la ironía del Quijote sin la fe de las Lusiadas?» ${ }^{68}$. En este mismo sentido, ya afirmaba en la referida carta sobre Camoens en 1923: «Si pudieran fundirse en un libro el espíritu del Quijote con el de las Lusiadas, ése sería el clásico de todo país en todo tiempo ${ }^{69}$. Esta integración cultural es preciso mantenerla como una constante, ya que «el alma española corre el grave peligro de morir de aridez en sus estepas como no vuelva a regarla, como la regó en el Siglo de Oro, la lírica portuguesa» ${ }^{70}$.

Este contraste e integración entre el lirismo portugués y el dramatismo castellano fue el eje de su conferencia del 13 de marzo de 1922 en el Ateneo, titulada «Portugal y su lirismo», que concluyó con la siguiente idea:

Si las almas castellanas se asomasen más a menudo a Portugal, se sentirían oreadas
por un viento perfumado, que las llamaría a una vida más llena. Si los portugueses
penetrasen en el alma castellana, hallarían en ella el secreto de una firmeza sólida y
callada, que daría al alma portuguesa la estabilidad que echan de menos su sensibi-
lidad y su heroísmo.

Un año después de su última «carta de Portugal», volverá a plantear el binomio Quijote-Lusiadas en otro artículo suyo en $\mathrm{El}$ Sol, titulado «Cara y Cruz» (16.XII.1924), dedicado nuevamente a explicar su necesaria integración mutua.

No deja de resultar llamativo el hecho de pese a estar aproximándose ya Maeztu hacia 1923 a su conversión religioso-política al tradicionalismo, sin embargo, en estas «Cartas» el elemento religioso tiene un menor peso cuantitativo y cualitativo respecto al cultural. La visión del Quijote como mitologema nacional maeztiano de estos textos aún no está tan subordinada al componente teológico-político como en el trasfondo historiográfico de sus obras posteriores, principalmente en su Defensa de la Hispanidad ${ }^{71}$. Pero tampoco se encuentra ya en la interpretación del Quijote marcada por el abatimiento, la decadencia y la melancolía, tan propia de su actitud regeneracionista inicial ${ }^{72}$.

Esta cierta subordinación de lo religioso a lo cultural puede detectarse incluso en la última carta portuguesa, de temática más netamente religiosa,

68 MARRERO, 1955: 439.

69 MAEZTU, «La epopeya...», artículo citado.

70 MAEZTU, «Portugal y su política» El Sol, 7.III.1923, p. 7.

71 Tomo el concepto del Quijote como «mitologema nacional» de VARELA OLEA, 2003: 26, 64 .

72 Para la versión del mitologema quijotesco en el regeneracionismo juvenil maeztiano, véase el análisis de Varela Olea sobre los artículos de Alma Española: «Don Quijote en Barcelona» (20.XII.1903) y «Ante las fiestas del Quijote» (13.XII.1903). 
donde Maeztu alude a la inquietud religiosa a través de la actitud trágica de busca a ciegas del célebre poeta luso Anthero de Quental (1842-1891), a quien pone a la altura de Verlaine, Baudelaire, o Leopardi, e incluso de Dante y de Shakespeare ${ }^{73}$. Este poeta, muy unido en la Coimbra de sus comienzos a Eça de Queiroz y a Teófilo Braga, y militante socialista junto a Oliveira Martins, pronto se convirtió en todo un símbolo del republicanismo intelectual y, tras su wertheriano suicidio en los jardines de un convento (1891), personificará el desgarro espiritual ante la búsqueda existencial de sentido y de trascendencia. Sobre el misticismo agónico de este Quental, afirma Maeztu:

Corazón místico, inteligencia escéptica, la lírica de Quental no expresa apenas más que el drama religioso del hombre que quiere creer y quiere, al mismo tiempo, ser veraz. Es el conflicto de dos lealtades contrapuestas.

Concluye Maeztu salvando a Quental: «El que llore por Dios está salvado. Poco importa, relativamente, que Quental lo niegue si sus lágrimas nos lo hacen desear». Puede que no anduviera el propio Maeztu muy lejos de esta misma situación interior no muchos años atrás, pero esta admiración ante la búsqueda atormentada y desesperada de Quental y esas referencias intelectuales -Verlaine, Baudelaire...- difícilmente hubieran tenido cabida en el Maeztu de Acción Española que advendrá casi una década después ${ }^{74}$.

Como colofón a estas reflexiones sobre Portugal en su etapa de transición, podría destacarse igualmente su artículo «Oliveira Martins», escrito en El Sol ${ }^{75}$ — escrito el mismo año en que finaliza la I República de Portugal, aunque no hace referencia a ello-. Pese a defender aquí la obra de este célebre polígrafo portugués de carácter republicano y socialista, a quien califica como «el más grande de los historiadores peninsulares», Maeztu ya incorpora al menos una conceptualización predominantemente católica y reivindicadora de la tradición cristiana. Cuando habla de cómo se decantan los pueblos ibéricos desde Islam hacia la Cristiandad, afirma: «Una vez decididos por la Cristiandad, encuentran en su decisión misma su razón de ser. La Cristiandad los empuja. ¿Adonde? A la universalización de la Cristiandad misma, es decir, al catolicismo, a la unidad católica ${ }^{76}$. Incluso llega a contraponer a Oliveira

73 En la obligada comparación con «el señor Unamuno», Maeztu atisba una superioridad moral en la búsqueda quentaliana ya que ve la búsqueda de Unamuno más intelectual que moral, mientras que Quental también busca en la eternidad un medio para preservar en ella la radicalidad de la bondad. La influencia de Quental sobre Unamuno fue muy intensa; para su análisis, véase: GARCÍA MOREJÓN, 1964, 209 y ss.

74 Aunque Gamallo Fierros destaca la comprensión que Maeztu muestra hacia diversos casos de suicidio en varios artículos, GAMALLO FIERROS, 1952, 1922-1923.

75 MAEZTU, «Oliveira Martins», El Sol, 21.XII.1926, 1, en su serie «Pareceres».

76 MAEZTU, «Oliveira Martins», El Sol, 21.XII.1926, 1, en su serie «Pareceres». 
Martins con su antagonista Menéndez Pelayo. Sin embargo, todavía no llega al punto de defender la postura tradicionalista de Menéndez Pelayo, sino que parece decantarse más bien por la postura del portugués al que considera más cercano, si bien desde cierto escepticismo, al ideal regeneracionista de Costa de buscar una conciliación entre sabiduría y riqueza - con su célebre «escuela y despensa»-, aspiración que Maeztu intenta completar desde la ampliación al ideal superior de «sabiduría, bondad y riqueza».

En uno de sus últimos textos sobre Portugal, escrito tan solo un año antes de morir, todavía plantea el binomio paralelo entre el carácter épico español y el «ethos» lírico portugués: «La naturaleza portuguesa es tan lírica como épica y dramática la de Castilla. Y por mucho que lo pienso, y lo vengo pensando hace bastantes años, no acierto a ver que pueda haber en ello ningún mal» ${ }^{77}$, concluye Maeztu. Este texto muestra que el tema de la vinculación entre España y Portugal fue una cierta constante, que no se vio sustancialmente afectada por su tradicionalismo posterior, aunque este sí que afectó más hondamente a su comprensión histórica sobre el pasado y el futuro religiosos de ambas naciones.

Sin embargo, cuando advino el Maeztu tradicionalista, su análisis político sí que sufrió un intenso viraje ideológico respecto a sus anteriores acercamientos a los líderes políticos e intelectuales de la I República de Portugal. Este viraje coincidirá además con el advenimiento del «Estado Novo» —o II República- (1933-1974) de Oliveira Salazar, un régimen con el que coincidirá en diversos elementos: corporativismo, municipalismo, defensa de la autoridad, crítica al sistema de partidos, tradicionalismo católico... Este cambio en el trasfondo de su análisis político sobre Portugal se hizo patente en una serie de cuatro artículos de 1935 dedicados a la alabanza de Salazar y de su «Estado Novo», con una entrevista personal incluida, como hiciera previamente respecto a los líderes de la I República ${ }^{78}$. Este último Maeztu considera que Salazar es la persona de autoridad, el cirujano de hierro, que necesitaba Portugal tras el «empantanamiento» en que la había sumido la República. Así, afirma Maeztu sobre Salazar:

Su mar tenebroso ha sido el presente Estado portugués, en déficit constante desde que vino la República. Sólo a fuerza de trabajo minucioso, de silencio, de concentración en su obra, de apartamiento de la política de tertulias, de los partidos, de los

77 Se trata de una tercera de $A B C$, «Lírica lusitana», 19.VI.1935; escrita un año antes de su muerte en el contexto de la «embajada cultural» a Lisboa junto a otros intelectuales europeos, a la que aludo a continuación. El artículo está firmado desde Estoril, en junio de 1935.

78 MAEZTU, Ramiro, «Oliveira Salazar», $A B C$, 7.VI.1935; «La autoridad», $A B C$, 19.VI.1935; «Lírica lusitana», $A B C, 19 . V I .1935$; «El Estado nuevo. Una entrevista con Oliveira Salazar», $A B C, 29$.VI.1935. 
clanes, ha podido salvar la hacienda en primer término, y convertir en servicios nacionales los capitales que antes se repartían la clientelas oligárquicas ${ }^{79}$.

En contraste con la postura filo-searista que había defendido en su artículo «Pesimismo, integralismo y republicanismo» de 1922, ahora compara positivamente a Salazar con el espíritu del infante Enrique y con el del rey Sebastián, poniéndolo en contraste con el espíritu «siniestro» del Marqués de Pombal «el terrible» ${ }^{80}$. Alude a la posibilidad de que ese sebastianismo funde, desde la «hispanidad», un «quinto imperio». Defiende la implantación de la dictadura pues el pueblo portugués «estaba ya cansado de los partidos y sus luchas. De aquí surge la fuerza moral de la Dictadura portuguesa», afirma ${ }^{81}$. Esta serie de artículos de junio de 1935 fueron fruto de un viaje a Portugal al que Maeztu fue invitado en ese mismo mes por el jefe de propaganda del «Estado novo», Antonio Ferro, junto a otros intelectuales españoles, incluido Unamuno, en una especie de «embajada cultural» de intelectuales europeos. Mientras que Unamuno hizo una serie de artículos muy críticos hacia el régimen dictatorial luso, Maeztu hizo un desarrollo del anterior acercamiento a Portugal pero transmutado por su nueva óptica ideológica. Seguramente, de haber continuado con vida, hubiera seguido analizando con agudo interés los experimentos corporativistas y municipalistas defendidos por el «Estado novo», así como su peculiar fusión de «dictadura académico-castrense»o «bélico-escolástica» que criticara Unamuno.

\section{CONCLUSIONES}

Del anterior análisis de la obra de Maeztu sobre el Portugal de la I República contenida en sus crónicas de 1910 y sobre todo en sus «Cartas de Portugal», se deduce la importancia creciente que fue adquiriendo el tema portugués para el vitoriano, cuestión que acabó integrando en su propuesta de «hispanidad», así como en el diseño ideológico de Acción Española. No olvidemos que la revista de Maeztu tuvo en el integralismo lusitano su principal inspiración fundacional, según reconoció el marqués de Quintanar, cofundador de la misma ${ }^{82}$.

La labor de contextualización histórico-biográfica, ha permitido esclarecer el contenido de estos textos desde sus dos géneros fundamentales: el de la

79 MAEZTU, «La autoridad», $A B C$, 19.VI.1935. Citado por P. G. Cuevas, 2003, 333.

80 MAEZTU, «Oliveira Salazar», $A B C$, 7.VI.1935, p. 1.

81 MAEZTU, «El Estado nuevo. Una entrevista con Oliveira Salazar», $A B C$, 29.VI.1935, 4.

82 QUINTANAR, 1960: s.p. Reconoce aquí la influencia fundacional sobre Acción Española del integralismo y de su órgano Naçao portuguesa, movimiento inspirado a su vez en la Action Française de Maurras. 
crónica de análisis político y el del ensayo cultural. Las dos crónicas de 1910, todavía pertenecientes ideológicamente a su primera etapa, nos muestran efectivamente a un Maeztu que justifica el proceso revolucionario hasta en los aspectos de su anticlericalismo. Mientras que en la serie «Cartas de Portugal», un Maeztu ya en transición realiza una crítica política de la situación republicana durante los convulsos años previos a su caída en 1926. En ella, aunque no evita las valoraciones negativas, parece desarrollar lo que podría denominarse un «criticismo interno» ya que manifiesta cierta afinidad para con el régimen republicano, al tiempo que se mantiene aún reacio hacia los elementos tradicionalistas, monárquicos e integralistas. Por otro lado, la vivencia directa de Maeztu en ese Portugal y su contacto personal con varios de los principales protagonistas de su I República es un dato que explica su vívido retrato de la realidad política y cultural portuguesas. Esa propensión de partida hacia el Portugal republicano y hacia sus intelectuales, irá disminuyendo con el crecimiento inverso de la variable religiosa, especialmente entre 1913 y 1926. Pero, en general, se trata de un periodo de cierta templanza ideológica $\mathrm{y}$ de equidistancia, que nos permite acceder a ese Maeztu intermedio que ha sido notablemente eclipsado por los maeztus extremos.

En este sentido, y sin detrimento de lo que la clasificación de Marrero tiene de consolidado por su claridad — más allá de su terminología —, la lectura de alguno de los textos maeztianos analizados en el presente artículo - junto a otros del mismo periodo-, sugieren la necesidad de revisar algunos de los contornos de su periodización, especialmente el relativo a la etapa de transición ideológica entre el Maeztu progresista y el tradicionalista.

Otra aportación relevante del análisis de estos textos es que nos ofrecen una clave para entender el desarrollo de su posterior noción, ya tradicionalista, de «hispanidad» en su complementariedad luso-española, cuestión que aunque tiene deudas inequívocas respecto al integralismo lusitano de Sardinha, era algo que en la mente y en la pluma de Maeztu ya estaba gestándose con anterioridad a sus enfoques tradicionalistas, lo cual obliga a matizar cierta contraposición que se ha hecho entre la «hispanidad» unamuniana y la maeztiana. Un claro ejemplo de ello es su ideal de la «integración del alma hispánica» que aparece ya en 1923.

\section{BIBLIOGRAFÍA}

Acedo Castilla, José, «En torno a Maeztu», Boletín de la Real Academia Sevillana de Buenas Letras, II, 2, 1974, 41-57.

Araquistain, Luis, «Cartas de Portugal», El Sol, (6 de noviembre, 1923).

Baiôa, Manuel, «A Primeira República Portuguesa (1910-1926): partidos e sistema político», Arbor, 190/766, marzo-abril (2014), 1-14. 
Baiôa, Manuel e Paulo Jorge Fernandes, «La Historia Política del Portugal Contemporáneo», Historia y Política, 7, 2002, 11-54.

Campos, Sérgio, «Da crise da Monarquia constitucional à Primeira República em Portugal (1890-1910)», en Hipólito de la Torre, España-Portugal: estudios de Historia contemporánea. Madrid, Universidad Complutense, 1998.

Carvalho, Paulo Archer de, «Da Naçao Portuguesa (1914-1938) ao Integralismo Lusitano (1932-1934): a insurreição dos intelectuais», en Revistas, Ideias e Doutrinas. Lecturas do pensamento contemporáneo, Lisboa, Livros Horizonte, 2003. 135-151.

Castro Leal, E., Partidos e Programas o campo partidário republicano português 1910-1926, Coimbra, Universidad de Coimbra, 2008.

Catroga, Fernando, «O Republicanismo Português (Cultura, história e política)», Revista da Faculdade de Letras -HISTÓRIA- Porto, III Série, 11, 2010, 95-119.

Cruz, Manuel Braga da, «O integralismo lusitano nas origens do salazarismo», Análise Social, XVIII/70, 1982, 137-182.

DeCoster, Cyrus C., «Varela y Portugal», Arbor, 33, Madrid, 1956, 398-410.

Englekirk, John «Entorno a Unamuno y Portugal», Hisppania, 42/1, Madrid, 1959, 32-39.

Fernandes, Rogério, «A Seara Nova e a primera república», Revistas, Ideias e Doutrinas. Leituras do pensamiento contemporâneo, Lisboa, Livros Horizonte, 2003, 83-90.

Gamallo Fierros, Dionisio, «Hacia un Maeztu total», Cuadernos Hispanoamericanos, 33-34, 1952, 466-467.

García Morejón, Julio, Unamuno y Portugal, Madrid, Cultura Hispánica, 1964.

González Cuevas, Pedro, «Sardinha y España», Razón Española, 74, 1995, 273-299.

González Cuevas, Pedro, Maeztu, biografía de un nacionalista español, Madrid, Marcial Pons, 2003.

Maeztu, Ramiro de, Artículos desconocidos (1897-1904), Ed. de Inman Fox, Madrid, Castalia, 1977.

Maeztu, Ramiro de, Defensa de la Hispanidad. Homo Legens, Madrid 2006 [1934].

Maeztu, Ramiro de, Hacia otra España, Bilbao, Cardenal, 1899.

Marques, A. H. de Oliveira, Afonso Costa, Lisboa, Arcadia, 1975.

Marrero, Vicente, Maeztu, Madrid, Rialp, 1955.

Martínez, Pedro Soares, A República Portuguesa e as Relaçóes Internacionais (1910-1926), Lisboa, Verbo Editora, 2001.

Medina, João, O Pelicano e a Seara. Integralistas e Seareiros juntos na revista Homens Livres, Lisboa, Edições António Ramos, 1978.

Ortega y Gasset, José, «El error Berenguer», El Sol, (15 de octubre 1930).

Pabón, Jesús, La Revolución Portuguesa, vol. II, Madrid, Espasa-Calpe. 1945.

Queiroz, Vasco de Barros, A República de 5 de Outubro de 1910 a Maio de 1926 e a acção política de Thomé José de Barros Queiroz, Eva, Lisboa, 1985.

Quintanar, Marqués de, Palabras..!, Madrid, edición no venal, 1960.

Reis, António, «Seara Nova: os anos da república», Revistas, Ideias e Doutrinas. Leituras do pensamiento contemporâneo, Lisboa, Livros Horizonte 2003, 61-82. 
Reis, António, «O grupo Seara Nova: Uma resposta das elites intelectuais à crise do sistema liberal», en M. Baiôa (ed.), Elites e Poder, Lisboa, Edições Colibri, 2004.

Reis, Carlos, Portugal ante la revolución de España: de Antero de Quental a Fernando Pessoa, Semiosfera, 2, (2014).

Roberts, Stephen G.H., "“Hispanidad": el desarrollo de una polémica noción en la obra de Miguel de Unamuno», Cuadernos de la Cátedra M. de Unamuno, 39, (2004), 61-80.

Rocha Relvas, Susana, «Valle Inclán y Portugal», Anales de Literatura Española Contemporánea, 32/3, Madrid, 2007, 107-130

Ruiz Serrano, Esteban, «Nietzsche y el pensamiento político español (1898-1931)», Res publica, 7, (2001), 69-121.

Sánchez Garrido, Pablo, «Sardinha y Maeztu: apología y subversión del liberalismo», en Pablo Sánchez Garrido y Consuelo Martínez Siclura (eds.) Miradas liberales. Análisis político en la Europa del S. XX, Madrid, Biblioteca Nueva, 2014, 203-229.

Sardinha, Antonio, La Alianza Peninsular, Madrid, Sáez Hermanos, 1930.

Serrão, Joel, Portugal. Del sebastianismo al socialismo, Lisboa, Seminarios y Ediciones, 1970.

Sobejano, Gonzalo, Nietzsche en España, Madrid, Gredos 1967.

Teixeira Nuno Severiano y Pinto, Antonio Costa (Coords.), A Primeira República Portuguesa. Entre o Liberalismo e o Autoritarismo, Lisboa, Edigóes Colibrí, 2000.

Torre, Hipólito de la, Antagonismo y fractura peninsular. España-Portugal 19101919, Madrid, Espasa, 1983.

Torre, Hipólito de la, Del "peligro español» a la amistad peninsular. EspañaPortugal 1919-1930, Madrid, UNED, 1984.

Valente, Vasco Pulido, A «República Velha» (1910-1917). Ensaio, Lisboa, Gradiva, 1997.

Varela Olea, Ma Ángeles, Don Quijote, mitologema nacional, Madrid, Centro de Estudios Cervantinos, 2003.

Villacañas, José Luis, Ramiro de Maeztu y el ideal de la burguesía en España, Madrid, Espasa-Calpe, 2000.

Vizcarra, Zacarías, «La rectitud de don Ramiro», en Cuadernos Hispanoamericanos, 33-34, 1952, 15-17.

Recibido: 17/03/2015

Aprobado: 07/10/2015 